\title{
A Novel Electrode Architecture for Monitoring Rifampicin in Various Pharmaceuticals
}

\author{
Rajasekhar Chokkareddy, Natesh Kumar Bhajanthri , Gan G Redhi ${ }^{*}$ \\ Electroanalytical Laboratories, Department of Chemistry, Durban University of Technology, P.O Box \\ 1334, Durban 4000, South Africa. \\ *E-mail: redhigg@dut.ac.za, nateshkumar786@gmail.com
}

doi: $10.20964 / 2017.10 .13$

Received: 24 March 2017 / Accepted: 25 July 2017 / Published: 12 September 2017

\begin{abstract}
The present work involves the fabrication of glassy carbon electrode (GCE) with iron oxide nanoparticles $\left(\mathrm{Fe}_{3} \mathrm{O}_{4} \mathrm{NPs}\right)$ and multiwalled carbon nanotubes (MWCNTs) composite. Further it was immobilized with Coenzyme q (Co en-q/ $\left.\mathrm{Fe}_{3} \mathrm{O}_{4} \mathrm{NPs} / \mathrm{MWCNT} / \mathrm{GCE}\right)$ to enhance the electrochemical performance of the modified electrode for the determination of rifampicin (RIF). The designed sensor was successfully characterized by Fourier transform infrared spectroscopy (FT-IR), transmission electron microscopy (TEM), thermo gravimetry (TGA) and x-ray diffraction (XRD) studies. The electrochemical oxidation of RIF has been studied by cyclic voltammetry (CV) and differential pulse voltammetric techniques (DPV). The enzyme immobilized sensor surface area was calculated and found to be $10.03 \mathrm{~mm}^{2}$. This larger surface area was responsible for the oxidation of more number of RIF molecules on the surface of sensor. The RIF shows two anodic peaks at $+0.10 \mathrm{~V}$ and $+0.72 \mathrm{~V}$ in phosphate buffer solution (PBS) $\mathrm{pH}$ 7.5. The cyclic voltammetric measurements reveals that the developed sensor exhibited an enhanced electrochemical platform with an approximately eight-fold increment in the anodic peak currents. Under the optimized conditions, a good linear relationship was observed between peak currents and RIF concentration. The studied linearity range $(2-20 \mu \mathrm{M})$ showed a limit of detection (LOD) of $0.032 \mu \mathrm{M}, 0.413 \mu \mathrm{M}$ and limit of quantification (LOQ) of 1.069 $\mu \mathrm{M}, 1.258 \mu \mathrm{M}$ for anodic peaks I and peaks II respectively. The proposed sensor showed longstanding stability and high reproducibility. The method was successfully applied for the determination of RIF in pharmaceutical tablets without any sample pre-treatment.
\end{abstract}

Keywords: Biosensor, Rifampicin, voltammetry, Co en-q, pharmaceutical samples

\section{FULL TEXT}

(C) 2017 The Authors. Published by ESG (www.electrochemsci.org). This article is an open access article distributed under the terms and conditions of the Creative Commons Attribution license (http://creativecommons.org/licenses/by/4.0/). 